\title{
WILLINGNESS TO ADOPT TECHNOLOGIES OF PRECISION AGRICULTURE: A CASE STUDY OF THE CZECH REPUBLIC
}

\author{
DRAHOMÍRA KUŠOVÁ ${ }^{1}$, JAN TĚS̆ITEL $^{2,3}$ \& ZUZANA BOUKALOVÁ ${ }^{3}$ \\ ${ }^{1}$ Faculty of Agriculture, University of South Bohemia České Budějovice, Czech Republic \\ ${ }^{2}$ College of Regional Development, Czech Republic \\ ${ }^{3}$ METCENAS o.p.s., Plzeň, Czech Republic
}

\begin{abstract}
The idea of precision agriculture is to optimize production inputs (fertilizers, irrigation water, etc.) when trying to achieve desired harvest. More targeted use of inputs is expected to benefit for the environment, including quality of underground water. It can be said to contribute to reconciling a situation frequently occurring in watershed, where the need to sustain high quality of water resources has to be balanced with other interests related to land-use. Technologies are available. Nevertheless, availability of technologies is a precondition necessary, but not sufficient. As in other cases, their practical implementation is influenced by many socio-economic and cultural factors, making any application site-specific. This paper builds on results of a sociological questionnaire survey conducted in selected rural areas of the Czech Republic. It tries to respond to the question to which extent factors such as tradition, overall economic situation, economic power of a farm and personality of a farmer can be considered predictors for willingness of a farmer to adopt precision agriculture technologies.

Keywords: precision agriculture, willingness to adopt, sociological survey, Czech Republic.
\end{abstract}

\section{INTRODUCTION}

Population growth has led to the situation of a still increasing pressure on resources. Drinking water and food are frequently mentioned in this respect, together with energy. As to the former two ones concerns they are considered to be geographically localised, in many cases they even coincide. The landscape (region, locality) is then presumed to simultaneously fulfil two functions - producing food and producing quality water to be used for drinking. Multiple functions imply multiple interests which are sometimes hard to balance and the functions can compete or even conflict. In Europe, market-driven agriculture tends to intensify in terms of inputs (nutrients and chemicals in general) with the aim to maximise production. Nutrient losses, however may affect quality of water resources of the area, both surface and underground. In the situation, when the turn to low input agriculture, though appearing, represents still only a marginal tendency compared with conventional intensive practices of agricultural production, new innovative technologies are searched for which could help to reduce harmful effects of chemicals used in agriculture on quality of soil and water (e.g. Tey and Brindal [1]).

Precision agriculture (also called precision farming) is frequently suggested as a promising way of development in this respect. Its central idea is to rationalize the inputs site-specifically, by use of variable rate treatment, supported as a rule by GIS and IT technologies (Lencsés, et al. [2]). The use of precision farming technology is thus supposed to result in a reduction of the amount of agrochemicals distributed in the environment, and it could also be one of the basic pillars of efficient agriculture, until large-scale production structure, investments, organizational structures and operational mechanisms remain. According to some estimations, you can achieve 20-60\% pesticide savings by use of o precision plant protection and up to $30 \%$ in fertilizer use depending on yield homogeneity (Rider et al. [3]). It seems to confirm the intuitive idea, that precision agriculture may reduce 
environmental loading, by applying chemicals only where they are needed and when they are needed (Bongiovanni [4]). At the same time, precision agriculture can meet the expectation of its users to increase efficiency of production, hence its profitability. Conceptually it is possible through a more cost-effective use of farm inputs (chemicals, fuel, labour and machinery), yield gain and selective harvesting (Chen et al. [5]). It is, however based on a presumption, that the net savings achieved by precision application are higher than the costs caused by either additional labour or the investment into specialised equipment, induced by the precision agriculture technologies (PAT) application (Tey and Brindal [1]). It is evident then, that the adoption of precision agriculture can be considered as a complex activity and there are many factors that influence these decision processes (Pierpaoli et al., [6]). Factors underlying adoption or no-adoption decisions can be found as subject of many analytical studies as well as studies having more general nature, reviewing these analytical ones. Farm size, land tenure, cost reduction, higher revenue, age and a degree of education of a farmer appear very frequently on the list, stressing economic aspect of application of PATs.

In the context outlined above, the contribution aims to contribute to the ongoing debate by use of data generated by the project FATIMA [17]. The main objective of the project is to establish innovative and new farm tools and service capacities that help the intensive farm sector to optimize its external input management (nutrients and water) and productivity, while protecting environment and social fabric. In practical terms, the project focuses both on development of particular technologies of precision farming and their site-specific applications, thematically spanning from technological to socio-cultural aspects of this challenge. In the frame of the project, sociological survey was conducted aimed to reveal overall socio-economic situation in agrarian sector and to identify factors that can modify a readiness of producers (and their willingness) to incorporate precision farming technologies into their farming practices, in rural areas of three European countries, Austria, Czech Republic and Italy. The article briefly reports on selected outputs of the survey conducted in the Czech Republic pilot area.

\section{MODEL AREA AND METHODS USED}

The FATIMA pilot area in the Czech Republic is situated in Bohemian-Moravian Highlands, i.e. in the region which serves as well as a resource area for drinking water. For the purpose of the survey, the model area was extended to provide more general picture as to the situation. In the end, it covered five rural districts located to the south of the country, with the same type of agriculture and the same or very similar water resource function.

As the basic set, producers of agricultural commodities were defined, which operated within the area of interest (mentioned above), meeting the condition of having at least the share of $80 \%$ of arable land on their total area. Out of them, the sample was derived by use of a combination of quota and random sampling, quota being share of producers in particular district on the total sum of producers. It ultimately yielded 250 respondents, distributed accordingly within the area. The questionnaire survey, thematically focused on factors influencing willingness of farmers to adopt PATs, was conducted in the period January-March 2017, and was realised by use of questioners, which ensured relatively high return of questionnaires (228 in total). The questionnaire survey was, subsequently, complemented with several in-depth interviews with selected producers, conducted by the authors themselves. Quantitative data were coded and analysed by use of the statistical software SPSS, v. 24, and visualised. Data from interviews were processed qualitatively. 


\section{RESULTS AND DISCUSSION}

The sample of agricultural enterprises can be described as composed mainly of long-time running family farms and "big" companies, mostly represented by agricultural cooperatives. Several join-stock companies appeared as well in the sample. Newly established family farms are relatively rare, which well reflects the present Czech reality. As to the size, enterprises dominate that managing the acreage between 50 to 100 hectares. They are mostly family farms whereas big companies are as a rule associated with the bigger size, making almost one third of our sample. Almost all, regardless of the size, do conventional agriculture. The majority of enterprises sampled face the situation of doing most of their business on land they do not own. As to the current situation they see it a relative optimistic way, or they are neutral. The typical owner of the farm (or manager of the agri-company) can be seen as a middleaged man, having passed secondary education specialised on agriculture or university. As such it is familiar with IT technologies and uses them for the purpose of his business as an everyday routine. The basic parameters of the sample are provided by the Table 1 .

As it is evident, three quarters of respondents have already adopted (some) precision farming technologies (Fig. 1). However, the sample appeared to be not homogenous in this respect. Size of the farm was identified as one of the sorting variables (Table 2).

Strong relationship which is likely to make the division of the sample was found on extremes - small and big enterprises. It seems to refer to the concept of "economy of scale" an important consideration in any attempt to acquire high level technologies. The concept is based on a rational assumption that larger farms have a greater capacity to absorb costs and risks, while at the same time allow those factors to be spread over a greater productive base.

Therefore, new technologies are more likely to be adopted on large farms (Walton et al. [7], Robertson et al. [8]). According to some researches, precision farming technology is profitable only above 250 ha, according to the others, farmers need a minimum of 1500 ha for precision weed management and fertilization. In the case of our sample, 1000 ha of arable land seem to make the divide.

Table 1: Basic parameters of the sample, $\mathrm{N}=228$. (Source: field survey data processed by the authors.)

\begin{tabular}{|c|c|c|c|c|}
\hline \multicolumn{5}{|c|}{ FARM LEVEL } \\
\hline \multirow{2}{*}{ category of the farm } & long-time operating farm & newly established farm & big company & \\
\hline & $53 \%$ & $8 \%$ & $39 \%$ & \\
\hline \multirow{2}{*}{ type of management } & conventional & ecological & & \\
\hline & $96 \%$ & $4 \%$ & & \\
\hline \multirow{2}{*}{ total acrage of arable land } & $>50$ ha & $51-100$ ha & 101 - 1000 ha & 1000 ha $<$ \\
\hline & $9 \%$ & $64 \%$ & $14 \%$ & $13 \%$ \\
\hline \multirow{2}{*}{$\begin{array}{l}\text { share of arable land owned on the } \\
\text { total acrage }\end{array}$} & $>25 \%$ & $26-50 \%$ & $51-75 \%$ & $75 \%<$ \\
\hline & $44 \%$ & $30 \%$ & $16 \%$ & $10 \%$ \\
\hline \multirow{2}{*}{$\begin{array}{l}\text { present situation as to the } \\
\text { investments into precision farming }\end{array}$} & goog time & bad time & neither good nor bad time & \\
\hline & $35 \%$ & $15 \%$ & $50 \%$ & \\
\hline \multirow{2}{*}{$\begin{array}{l}\text { recent application of precission } \\
\text { farming technologies }\end{array}$} & yes & no & & \\
\hline & $74 \%$ & $26 \%$ & & \\
\hline \multicolumn{5}{|c|}{ RESPONDENT LEVEL } \\
\hline \multirow{2}{*}{ gender } & male & female & & \\
\hline & $90 \%$ & $10 \%$ & & \\
\hline \multirow{2}{*}{ age } & $>40$ years & $41-54$ years & 55 - 65 years & 65 years $<$ \\
\hline & $29 \%$ & $51 \%$ & $19 \%$ & $1 \%$ \\
\hline \multirow[t]{2}{*}{ education } & $\begin{array}{l}\text { vocational/specialised } \\
\text { secondery school }\end{array}$ & secondary/ high school & university & \\
\hline & $45 \%$ & $17 \%$ & $38 \%$ & \\
\hline \multirow{2}{*}{$\begin{array}{l}\text { using smart phone for professional } \\
\text { purposes }\end{array}$} & yes & no & & \\
\hline & $72 \%$ & $28 \%$ & & \\
\hline \multirow{2}{*}{$\begin{array}{l}\text { using computer for professional } \\
\text { purposes }\end{array}$} & yes & no & & \\
\hline & $100 \%$ & $0 \%$ & & \\
\hline \multirow{2}{*}{ connection to the Internet } & yes & no & & \\
\hline & $100 \%$ & $0 \%$ & & \\
\hline
\end{tabular}




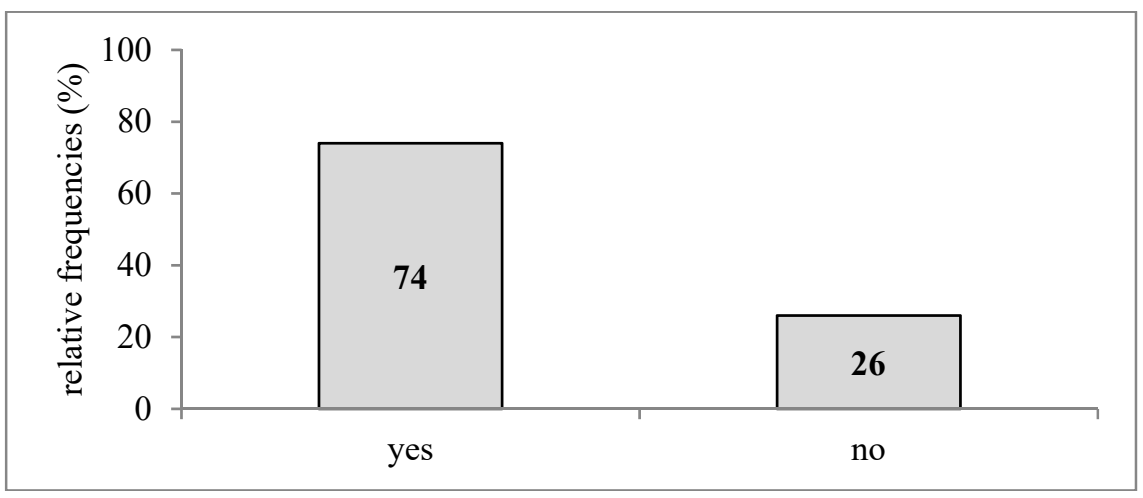

Figure 1: Recent adoption of precision agriculture technologies, $\mathrm{N}=228$. (Source: field survey data processed by the authors.)

Table 2: Relationship between PA technologies application and the size of the agri-enterprise, adjusted standardised residuals, $\mathrm{N}=228, \mathrm{p}=0,000 \ldots$ (Source: field survey data processed by the authors.)

\begin{tabular}{|c|c|c|c|c|c|}
\hline & \multicolumn{4}{|c|}{ Total acreage of arable land } \\
\hline & & $<50$ ha & $51-100$ ha & $101-1000$ ha & $1000 \mathrm{ha}<$ \\
\hline \multirow[t]{2}{*}{ Adoption } & Yes & -5.8 & 1.5 & 0.1 & 2.6 \\
\hline & No & 5.8 & -1.5 & -0.1 & -2.6 \\
\hline
\end{tabular}

Table 3: Relationship between the PA technologies application and share of land owned and rented, adjusted standardised residuals, $\mathrm{N}=228, \mathrm{p}=0,00 \ldots$ (Source:field survey data processed by the authors.)

\begin{tabular}{|l|c|c|c|c|c|}
\hline \multicolumn{2}{|c|}{} & \multicolumn{5}{|c|}{ Share of arable land owned on the total acreage } \\
\cline { 3 - 6 } & & $<25 \%$ & $26-50 \%$ & $51-75 \%$ & $75 \%<$ \\
\hline \multirow{2}{*}{ Adoption } & Yes & 0.0 & $\mathbf{3 . 6}$ & -1.5 & $\mathbf{- 3 . 7}$ \\
\cline { 2 - 6 } & No & 0.0 & $\mathbf{- 3 . 6}$ & 1.5 & $\mathbf{3 . 7}$ \\
\hline
\end{tabular}

Table 4: Relationship between the PA technologies application and the age of the farmer/manager, adjusted standardised residuals, $\mathrm{N}=228 ; \mathrm{p}=0,00 \ldots$ (Source: field survey data processed by the authors.)

\begin{tabular}{|c|c|c|c|c|c|}
\hline & \multicolumn{4}{|c|}{ Age } \\
\hline & & $<40$ years & $40-54$ years & $55-65$ years & $<65$ years \\
\hline \multirow[t]{2}{*}{ Adoption } & Yes & -0.3 & -2.0 & 2.6 & 1.0 \\
\hline & No & 0.3 & 2.0 & -2.6 & -1.0 \\
\hline
\end{tabular}

Legend for tables 2 to 4 :

If the value of adjusted standardised residuals $>3$, it indicates a dependency between particular values of a row and column variables. The p-value is the level of marginal significance within a statistical hypothesis test representing the probability of the occurrence of a given event. The p-value is used as an alternative to rejection points to provide the smallest level of significance at which the null hypothesis would be rejected. A smaller pvalue means that there is stronger evidence in favour of the alternative hypothesis. 
The relative big variability in acreage allowing adoption of precision agriculture is obviously explained by differing local conditions as the economical threshold level highly depends on the correlation between savings and additional costs which is strongly determined by heterogeneity of particular plots where the technologies are applied (Lencsés et al. [2]).

The relation between adoption of PATs and land tenure, articulated in terms of the share of land owned and land rented is a bit difficult to interpret (Table 3). In the literature, it is generally expected that a farmer is more likely to manage self-owned land in a more favourable manner than rented one (Roberts et al. [9]). With such ownership, he is supposed to more likely enjoy the benefits accruing to his farm management and, thus, increase the incentive for the adoption of PATs (e.g. Roberts et al. [10], Isgin et al. [11]). In our case, the relevance does not manifest "linearity" in the sense that "the more owned land, the higher the rate of adoption". Significant "pro-adoption" behaviour was identified under the condition of the farmer owning up to the half of the land he managed. Surprisingly, the share of $75 \%$ and more owned land was associated with significantly high "non-adoption" behaviour. The reason why is still open for discussion and further in-depth research.

In some studies, age was identified as a significant explanatory factor, which has a negative relationship with the adoption of high-technological practices (Batte and van Buren [12]). This was considered to be a consequence of older farmers having shorter planning horizons, diminished incentives to change and less exposure to PATs, mainly due to their hesitation to use the computer (Roberts et al. [9]). In this context, younger farmers were postulate as having longer career horizon and being more technologically orientated (Larson et al. [13]). Other studies, on the other hand found age as a positive determinant (e.g. Isgin et al. [11]) or an insignificant factor (e.g. Daberkow and McBride [14], Robertson et al. [8]). In our case, age proved to be significant positive predictor of adoptive decision. Based on our date we would suggest the age of 55 is important in this respect (Table 4). To discuss this point we can say that "age" itself is sometimes used as a proxy of "openness to new things to come" which implicitly supposes older farmers (managers) to be less open to new technologies included IT ones. It seems not to be the case of the Czech Republic. As can be seen from Table 1, most farmers/managers, regardless of age, use routinely smart phones in their work all of them use computers for professional purposes, connected to the Internet, as agricultural enterprises have to communicate with state administration by use of the software Agronom ${ }^{\circledR}[18]$.

Hence, openness to new technologies did not prove to appear as a predictor of pro adoption decision in our case. Another association of age could be then considered as a base for further discussion, namely association of "age" with "experience". This is variable, however, is reported as having ambiguous impact on the adoption. Greater experience can lead to better knowledge of spatial variability in the field (Khanna [15]) and to operational efficiency to the extent that farmers learn by doing (Adhikari et al. [16]). More experienced farmers may then feel less need for the supplementary information provided by new technologies, which can lead to lower rate of adoption (Isgin et al. [11]). On the other hand, uncertainty regarding farm investment decreases with learning and experience. This may induce farmers to adopt PATs as long as they are profitable (Daberkow and McBride [14]).

Economic considerations appeared to be an important aspect in adoption decision, as can be documented by ranking factors that were taken into consideration (Fig. 2). Improvement of groundwater quality as well as technological aspects of adoption can be found in the lower part of the graph, having lower total score compared to economic aspects, articulated in terms of "investment costs", "potential of yield increase" and "reduction of inputs in terms of nutrients". 
The relation to the environment quality, in terms of responsibility for it, can be well documented by the series of three following graphs. They reflect attitudes of respondents to three statements concerning the role of agriculture in the care of the environment. On this basis, it is then possible to estimate their real behaviour.

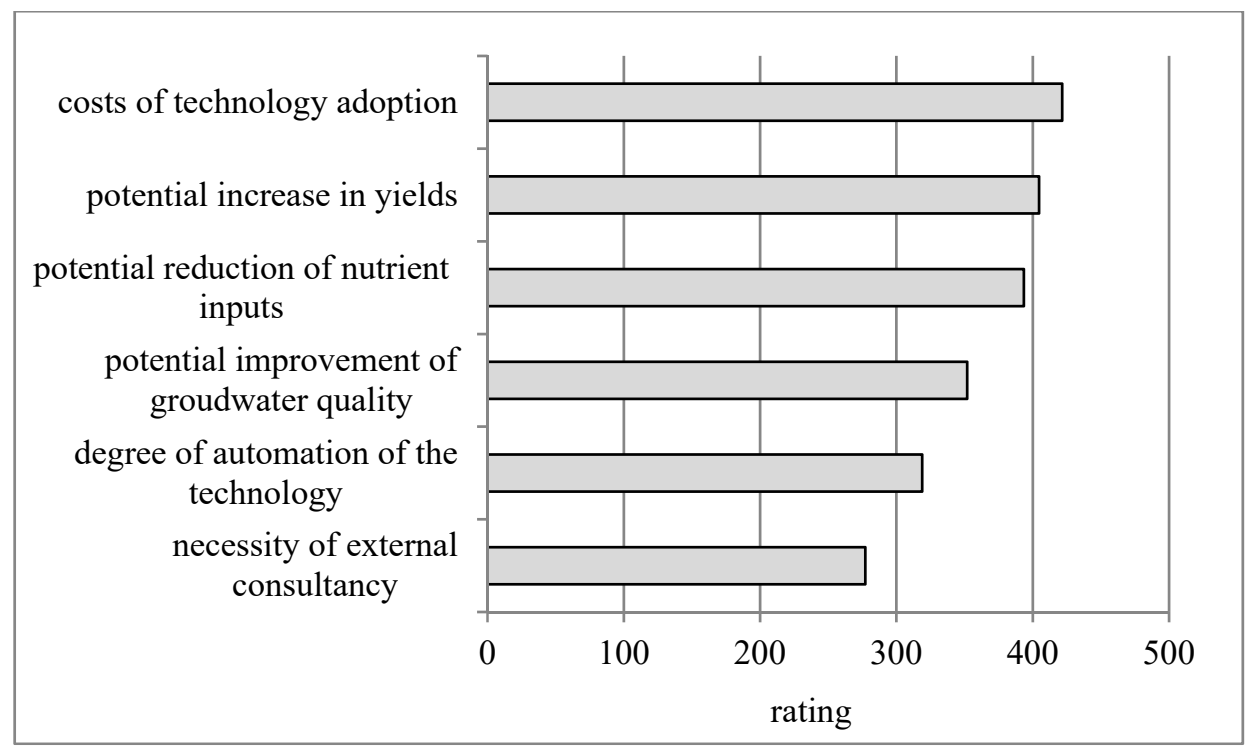

Figure 2: Importance of factors taken into consideration when adopting precision farming technologies, $\mathrm{N}=228$, minimum rating $=100$, maximum rating $=500$. (Source: field survey data processed by the authors.)

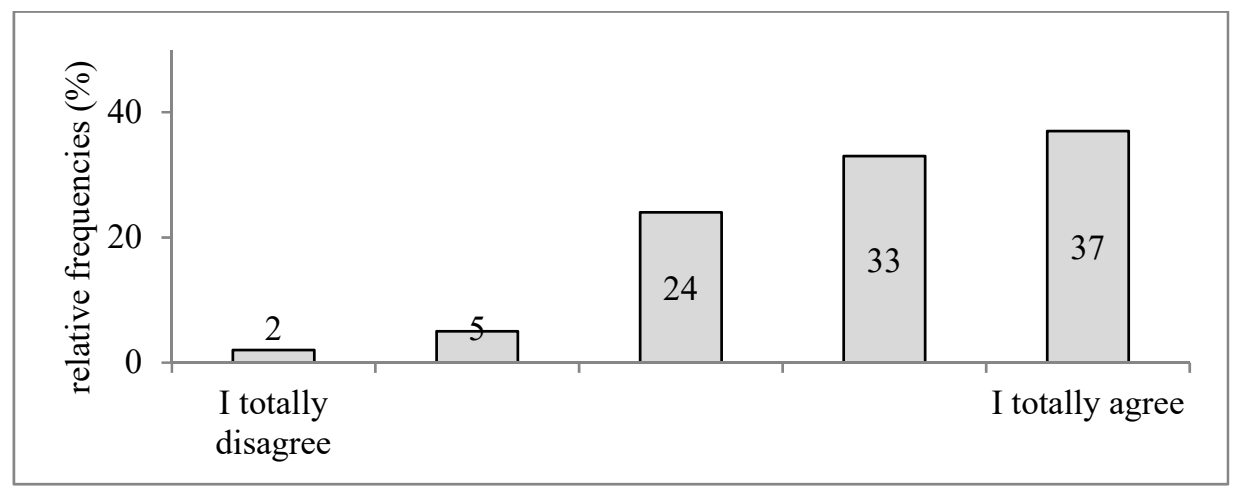

Figure 3: Attitude to the statement "Farmers have the obligation to contribute to nature protection as much as possible.", $\mathrm{N}=228$, degree of an agreement with the statement is valued on the 5-point ordinal scale, with $1=$ "totally disagree" up to 5 = "totally agree". (Source: field survey data processed by the authors.) 


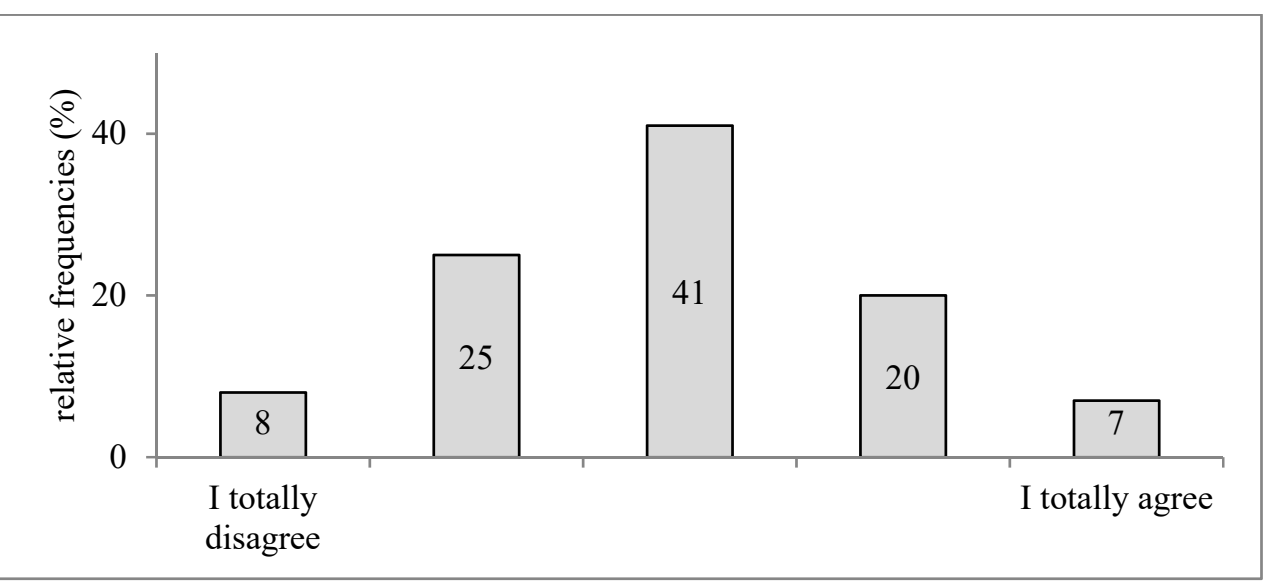

Figure 4: Attitude to the statement "I am willing to take nature protection measures on my farm even if it is at the expense of revenues.", $\mathrm{N}=228$, degree of an agreement with the statement is valued on the 5-point ordinal scale, with $1=$ "totally disagree" up to $5=$ "totally agree". (Source:field survey data processed by the authors.)

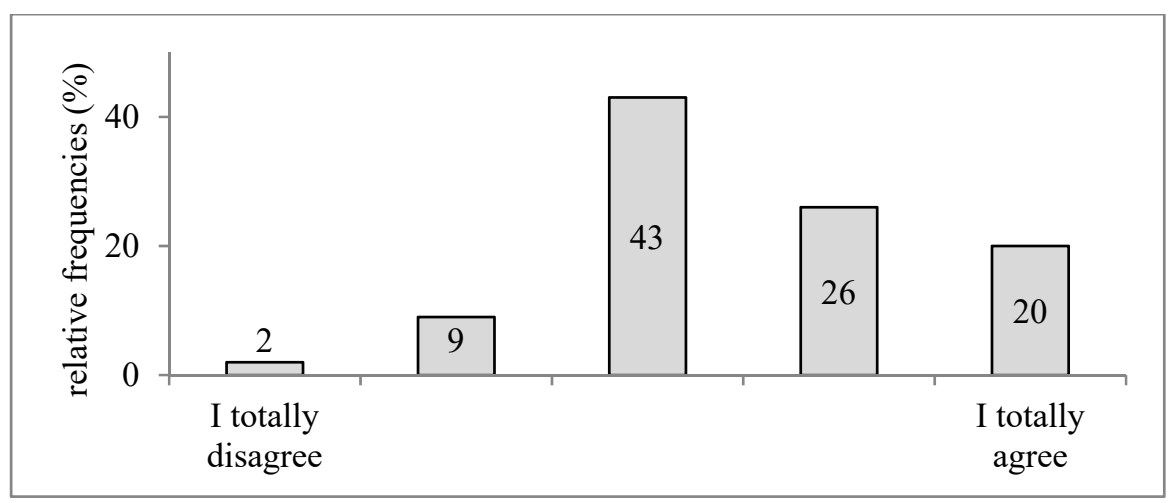

Figure 5: Attitude to the statement "The negative environmental effects of farming are often overestimated.", $\mathrm{N}=228$, degree of an agreement with the statement is valued on the 5-point ordinal scale, with 1 = "totally disagree" up to 5 = "totally agree". (Source: field survey data processed by the authors.)

They agreed, on the general level, with the suggestion, that agriculture should play the role of landscape steward (Fig. 3), prolonging thus traditional image ascribed historically to agriculture, regardless of its recent development which made it in many cases industry-like activity of production. When asked, however, to contribute to the environment quality practically, at the expense on their revenues, they manifest more hesitative standpoint (Fig. 4), supported likely with their strong belief of agriculture being blamed unjustly for environmental damages (Fig. 5), that emphasised again their self-image of being "good stewards". 


\section{CONCLUSIONS}

To briefly summarize we could say, that the adoption of precision agriculture technologies is relatively high in the Czech Republic. It is not much surprising, that within the marked-driven economy, market-driven factors dominate in the process of adoption decision. The environment-driven factors are obviously taken into consideration only as the second in the order, which is partly supported by the belief of the farmers not interfering much with the environment. Among the economic factors, farm size represents positive correlation, having in the case of our sample 1000 ha as a "critical" acreage which is supposed to allow utilisation of the economy of scale effect. Analysis of land tenure, in terms of land ownership, provided surprising outputs, which are to be analysed in more detail. Unlike of some other studies, education and familiarity with IT technologies did not appear to be predictors for adoption of precision agriculture. The latter evidently due to the fact, that state administration widely uses IT platform to communicate with farmers.

\section{ACKNOWLEDGEMENTS}

The publication was financially supported by the project Farming Tools for external nutrient Inputs and water Management (FATIMA) (2015-2018), realised within the Horizon 2020 research and innovation programme under grant agreement No 633945.

\section{REFERENCES}

[1] Tey, Y.S. \& Brindal, M., Factors influencing the adoption of precision agricultural technologies: A review for policy implications. Precision Agriculture, 13, pp. 713-730, 2012.

[2] Lencsés, E., Takács, I. \& Takács-György, K., Farmers’ perception of precision farming technology among Hungarian farmers. Sustainability, 6, pp. 8452-8465, 2014.

[3] Rider, T.W., Vogel, J.W., Dille, J.A., Dhuyvetter, K.C. \& Kastens, T.L., An economic evaluation of site-specific herbicide application. Precision Agriculture, 7, pp. 379-392, 2006.

[4] Bongiovanni, R., Precision agriculture and sustainability. Precision Agriculture, 5, pp. 359-387, 2004.

[5] Chen, W. et al., Key crop nutrient management issues in the Western Australia grains industry: A review. Australian Journal of Soil Research, 47, pp. 1-18, 2009.

[6] Pierpaoli, E., Carli, G., Pignatti, E. \& Canavari, M., Drivers of precision agriculture technologies adoption: A literature review. Procedia Technology, 8, pp. 61-69, 2013.

[7] Walton, J.C. et al., Adoption and abandonment of precision soil sampling in cotton production. Journal of Agricultural and Resource Economics, 33(3), pp. 428-448, 2008.

[8] Robertson, M.J. et al., Adoption of variable rate fertiliser application in the Australian grains industry: status, issues and prospects. Precision Agriculture, 13, pp. 181-199, 2012.

[9] Roberts, R.K. et al., Adoption of site-specific information and variable-rate technologies in cotton precision farming. Journal of Agricultural and Applied Economics, 36(1), pp. 143-158, 2004.

[10] Roberts, R.K., English, B.C. \& Larson, J.A., Factors affecting the location of precision farming technology adoption in Tennessee. Journal of Extension, 40(1), Online. Article 1RIB3, http://www.joe.org/joe/2002february/rb3.php. 2002.

[11] Isgin, T., Bilgic, A, Forster, D.L \& Batte, M.T., Using count data models to determine the factors affecting farmers' quantity decisions of precision farming technology adoption. Computers and Electronics in Agriculture, 62, pp. 231-242, 2008. 
[12] Batte, M. \& Van Buren, F., Precision farming - Factors influencing profitability. Proceedings of the Northern Ohio Crops Day Meeting, USA, 1999.

[13] Larson, J.A. et al., Factors affecting farmer adoption of remotely sensed imagery for precision management in cotton production. Precision Agriculture, 9(4), pp. 195-208, 2008.

[14] Daberkow, S.G. \& McBride, W.D., Farm and operator characteristics affecting the awareness and adoption of precision agriculture technologies in the US. Precision Agriculture, 4(2), pp. 163-177, 2003.

[15] Khanna, M., Sequential adoption of site-specific technologies and its implications for Nitrogen productivity: A double selectivity model. American Journal of Agricultural Economics, 83(1), pp. 35-51, 2001.

[16] Adhikari, A., Mishra, A.K. \& Chintawar, S., Adoption of technology and its impact on profitability of young and beginning farmers: A quantile regression approach. Paper presented at the Southern Agricultural Economics Association Annual Meeting, Georgia, USA, 2009.

[17] FATIMA, Online. http://fatima-h2020.eu/.

[18] Agronom $^{\circledR}$ Online. http://www.aginfo.cz/joomla/index.php/programy/rostlinnavyroba/agronom?gclid=CJCPmMu-_tQCFeoy0wodVgECtQ. 